\title{
De redes sociais a comunidades de prática: um estudo sobre percepção e efetivação de affordances no ambiente on-line
}

\author{
From social networks to communities of practice: a study about perception and \\ effectivity of affordances in the online environment
}

\begin{abstract}
Resumo: Lima (2009) afirma que a aprendizagem da língua inglesa tem se justificado desde a questão de status à real necessidade de se comunicar com um mundo sem fronteiras. Consciente da importância da aprendizagem dessa língua nos dias atuais, marcados por questões tecnológicas, proponho pesquisar como alguns ambientes on-line influenciam essa aprendizagem em alunos de uma escola de idiomas em Uberaba, Minas Gerais. Para tanto, recorro ao conceito de affordances, termo cunhado por Gibson (1986), que tem sido utilizado atualmente na área de Linguística Aplicada. Esse termo significa tudo o que um ambiente pode proporcionar a um individuo. Sendo assim, acredito que esses ambientes on-line, que incluem as redes sociais, são repletos de affordances a serem efetivadas para a aprendizagem de língua inglesa. Acredito, ainda, que tais redes sociais são ambientes propícios para a emergência de comunidades de prática (WENGER; MCDERMOTT; SNYDER, 2002). Ao analisar questionários, contendo narrativas das experiências desses alunos com a língua inglesa em ambientes on-line, concluo que eles percebem e efetivam diferentes affordances nesses ambientes, porém tendem a não utilizar as redes sociais como comunidades de prática.
\end{abstract}

Palavras-chave: aprendizagem de língua inglesá; affordances; redes sociais; comunidades de prática.

Abstract: Lima (2009) claims that learning English has been justified by matters of status to the real need to communicate with a world without boundaries. As I am aware of the importance of learning this language nowadays, a time marked by technological issues, I propose to research how some online environments influence English learning in students of an English institute in Uberaba, Minas Gerais. In order to do so, I resort to the concept of affordances, term coined by Gibson (1981), which has been used in Applied Linguistics. This term means what the environment can provide for individuals. In this way, I believe online environments, which include social networks, are full of affordances to be brought into action for the learning of the English language. I also believe that these social networks are favorable environments to the emergence of communities of practice (WENGER; MCDERMOTT; SNYDER, 2002). Analyzing questionnaires, containing narratives of these students' experiences with the English language in online environments, I have concluded that students perceive and bring into action different affordances from these environments, but they tend not to use social networking as communities of practice.

Keywords: English learning; affordances; social networking; communities of practice.

\footnotetext{
* Aluna do curso de Pós Graduação em Especialização em Ensino de Línguas Mediado por Computador da Universidade Federal de Minas Gerais (UFMG). Graduada em Letras - Português/Inglês pela Universidade Federal do Triângulo Mineiro, danivalim@hotmail.com;
} 


\section{Introdução}

Dudeney (2000), em sua introdução do livro "The internet and the language classroom" afirma que a internet tem sido descrita como a maior revolução comunicativa desde o advento dos livros escritos, apesar de até pouco tempo atrás ter sido um campo aproveitado apenas por um grupo restrito de pessoas. Entretanto, essa realidade atualmente tem mudado, como podemos observar nas palavras do autor:

Esses dias, porém, as coisas mudaram para melhor, e a rede de computadores é agora uma próspera comunidade com muitos milhões de pessoas trocando informações, ideias e opiniões. O desenvolvimento de conexões mais fáceis, mais programas de fácil uso (...) e um acesso mais barato abriu a "superestrada da informação" para todos, desde crianças pequenas - em casa e na escola - aos profissionais em todas as áreas e esferas da vida (DUDENEY, 2000, p. 1) ${ }^{1}$.

Apesar da maior acessibilidade à internet, devemos lembrar que muitas pessoas não possuem acesso a essa tecnologia, o que impede uma generalização. De certa forma, o que temos visto, com frequência, são grupos de crianças, desde pequenas, entrando em contato com vídeo games, celulares, dentre outras tecnologias, e a internet geralmente está incluída nesse contato. Segundo dados e projeções recentes sobre a internet no Brasil ${ }^{2}$, somos 81,3 milhões de internautas, com idade a partir de doze anos.

O contato com as novas tecnologias tem sido explorado por Prensky (2001), que nos apresenta algumas reflexões acerca dos conceitos de nativos e imigrantes digitais. O autor pontua que o perfil dos alunos mudou radicalmente e o sistema educacional atual não foi desenvolvido para eles. Seus modos de aprender e processar informações se diferenciam daqueles de seus pais e professores.

Temos, então, duas gerações: a dos nativos digitais, que foram socializados e ambientados à linguagem presente nos computadores, nos jogos de vídeo e on-line e na internet. Em contrapartida, temos os imigrantes digitais, que em algum ponto de sua vida precisaram ou quiseram se ambientar a esse mundo tecnológico, mas possuem características marcantes que os diferenciam da outra geração. De acordo com o autor, podemos associar essa ambientação às questões linguísticas.

Há centenas de exemplos de sotaque de um imigrante digital. Eles incluem imprimir um e-mail recebido (ou pedir para que sua secretária o faça, o que faz com que você tenha um sotaque mais marcado); precisar imprimir um

1 Essa e demais traduções são de minha responsabilidade.

2 Para mais informações, acessar o site $<\mathrm{http}$ ://tobeguarany.com/internet_no_brasil.php.> 
documento de seu computador para modificá-lo (em vez de simplesmente fazer isso no próprio computador) (...) Nós, os imigrantes digitais, podemos e devemos rir de nós mesmos e de nosso 'sotaque' (PRENSKY, 2001, p.2).

Mesmo citando o trabalho de Prensky (2001), é importante apontar as limitações de sua proposta. A polaridade nativo e imigrante deve ser repensada em termos de um continuum, pois essa suposta natividade, a meu ver, está muito mais relacionada às experiências e ao contato com as novas tecnologias de informação e comunicação do que simplesmente a faixa etária das pessoas.

Os nativos digitais possuem hoje acesso a qualquer informação através da internet. As redes sociais presentes na web, como Orkut e Facebook, por exemplo, tornam possíveis essas trocas de informações. Esses sites agrupam pessoas de diferentes locais, e na maioria das vezes, com interesses similares, ou seja, algo em comum as aproxima.

Faz-se necessário refletir que o idioma que atualmente mais possibilita essa comunicação é a língua inglesa, língua esta falada praticamente em todo o mundo. Lima (2009) afirma que a necessidade de aprender a língua inglesa tem se justificado por razões que vão de status à real exigência de dialogar com um mundo sem fronteiras. Sua aprendizagem tem se tornado recorrente no Brasil para os alunos de ensino Fundamental e Médio, e em escolas de idiomas voltadas para o ensino dessa língua.

As Orientações Curriculares Nacionais, documento atual acerca do ensino do inglês no Brasil, no Capítulo 3, acerca de conhecimentos de línguas estrangeiras, afirma que um dos seus objetivos é introduzir as teorias sobre linguagem e as novas tecnologias, oferecendo sugestões sobre a prática de seu ensino com o auxílio tecnológico. Uma sugestão que na teoria é adequada, visto que o mundo que vivemos atualmente é movido a tecnologias. Isto levaria a uma inclusão digital e social, por exemplo, conscientizando os alunos que há outras formas de produção e circulação da informação (BRASIL, 2006, p.97).

Sendo assim, este estudo justifica-se inicialmente pelo fato de que a língua inglesa fazse presente na vida dos alunos, não apenas através das tecnologias digitais, mas da escola, que tem o papel de ensinar esse idioma para eles. Justifica-se ainda por esses alunos se interessarem por diversas atividades on-line, entre elas redes sociais, participando ativamente e diariamente, com grande interesse. 
O objetivo deste trabalho é pesquisar como alunos de uma escola de idioma da cidade de Uberaba, Minas Gerais percebem e efetivam as affordances ${ }^{3}$ presentes no ambiente on-line para a aprendizagem de língua inglesa.

Em um primeiro momento, analisei se os alunos utilizam recursos tecnológicos para a aprendizagem de língua inglesa e, caso afirmativo, quais são esses recursos. Em um segundo momento, busquei saber quais são as redes sociais on-line que esses alunos usam, e se através delas eles dizem aprender ou aprimorar o conhecimento que possuem em língua inglesa, e ainda, como eles fazem isso. Depois, procurei entender se a partir dessa participação em redes sociais, esses alunos passam a ser membros de comunidades de prática propiciadoras de aprendizagem de língua inglesa.

Após essa introdução, apresento a base teórica em duas seções. Posteriormente, discorro sobre a metodologia e depois analiso os questionários aplicados aos participantes. Por fim, apresento as considerações finais da pesquisa.

\section{Efetivação de affordances: possibilidades na relação usuário-ambiente.}

O termo affordances, cunhado por Gibson (1986) em seus estudos acerca de percepção visual, investiga a relação entre organismos e elementos do ecossistema. O autor nos oferece a seguinte definição: "as affordances do ambiente são aquilo que ele oferece ao animal, o que provê ou proporciona, mesmo sendo bom ou ruim" (GIBSON, 1986, p.127).

Gibson (1986) pontua que o verbo to afford é dicionarizado e segundo o dicionário LONGMAN (2004, p. 17) significa "prover algo ou permitir que algo aconteça". Porém, o substantivo affordance não é, pois ele criou essa palavra para se referir à relação entre ambiente e animais que nenhum outro termo seria capaz de fazê-lo. Um exemplo de affordance apresentado por ele diz respeito às superfícies terrestres: uma trilha na floresta te propicia caminhar e uma superfície com água te propicia nadar.

Ele enfatiza, porém, que as affordances são relativas, dependendo assim da relação que o indivíduo tem com o ambiente. Isso significa que um mesmo local pode oferecer diferentes affordances, assim como um mesmo objeto pode ser percebido de maneiras distintas. Uma brincadeira recorrente em minha infância pode ilustrar bem esse fato. Quando criança, eu adorava brincar de bonecas, porém, quando ia passar o dia em minha bisavó e

\footnotetext{
${ }^{3}$ Conceito discutido na próxima seção.
} 
esquecia de levá-las, utilizava meus lápis como bonecas. As cores mais femininas, como rosa e amarelo, eram as bonecas e as masculinas, como azul e verde, os bonecos. Minha bisavó nunca entendia o que eu estava fazendo com um monte de lápis e falando sozinha. Ela não efetivava a affordance que eu estava efetivando.

Seguindo essa linha de pensamentos, considero importante entender a concepção de effectivities, que complementa affordances, que se limitam às propriedades do ambiente que possibilitam ações no contexto. O conceito de effectivities está relacionado às habilidades dos indivíduos dentro deste mesmo contexto (YOUNG; BARAB; GARRET, 2000). Voltando ao exemplo do lápis, observamos que uma das affordances que ele possibilita é escrever, mas para realizar essa ação o indivíduo precisa possuir as effectivities necessárias, o que não aconteceria se o sujeito não possuísse os movimentos dos braços, por exemplo.

O conceito de affordance tem sido muito usado na área de Linguística Aplicada. Para Van Lier (2004), tal palavra diz respeito àquilo que está disponível para alguém fazer algo e que emerge ao interagimos com o mundo físico e social. Essa visão tem influenciado o modo como vemos a aprendizagem de uma língua. Van Lier (2004) defende que os aprendizes são imersos em ambientes repletos de possibilidades significativas. Para ele "a percepção, ação e interpretação, em um ciclo contínuo de reforço mútuo, são condições prévias para o surgimento de sentido" (VAN LIER, 2004, p.92).

Outro conceito usado pelo autor, e relacionado ao de affordances, é o de emergência. Segundo Van Lier (2004) ela ocorre quando organismos ou elementos simples se reorganizam em algo mais complexo, em sistemas mais inteligentes. Um exemplo oferecido pelo autor é o de uma colônia de formigas: uma formiga sozinha não consegue obter os mesmos resultados que um grupo delas. Tente tirar uma das formigas em fila para ver a desordem causada. Isso mostra que, para elas obterem resultados, precisam umas das outras.

Nessa mesma perspectiva, Paiva (2010) afirma que a emergência acontece quando se responde às oportunidades de interação, para as exigências e restrições, ou para ofertas e obstáculos, reorganizando, adaptando-se às condições mutáveis em um nicho. A autora enfatiza que as affordances não são propriedades dos ambientes, como já citado anteriormente, e que uma prova é o fato de cada indivíduo ter diferentes percepções do mundo e que da interação que eles possuem com esses ambientes emergem diferentes práticas sociais. 
Ao pensarmos nas redes sociais presentes na internet atualmente, nos parece claro que assim como qualquer outro ambiente, elas estão repletas de affordances a serem efetivadas. Ainda nessa linha de pensamento, os alunos de uma língua estrangeira podem ampliar seu conhecimento através da interação com outras pessoas que possuem o mesmo interesse, havendo assim uma emergência. Na sequência apresento a questão das redes sociais e comunidades de prática, para que assim possamos iniciar as análises em busca das respostas para as perguntas propostas.

\section{Redes sociais: possibilidade de emergência de comunidades de prática.}

Em seu livro "Cultivating communities of practice", Wenger, Medermott e Snyder (2002) explicam o que são as comunidades de prática através do exemplo de um grupo de engenheiros que se uniram dentro de uma empresa e que, juntos desenvolveram um trabalho muito produtivo.

Engenheiros descobriram que a participação ajuda a fazer melhor seu trabalho, e o tempo que passam juntos é um bom investimento. Muitas vezes economiza-se tempo mais tarde para eles e aumenta a confiança nos seus próprios projetos. Dá-lhes uma chance de obter ajuda com problemas específicos, para saber o que os outros estão descobrindo e explorar novas tecnologias (WENGER; MCDERMOTT; SNYDER 2002, p.3).

Os autores dizem que as comunidades de práticas são grupos de pessoas que dividem mesmos problemas ou paixão por um tópico. Algumas dessas comunidades possuem nome, como o caso da dos engenheiros, que se chamava "The Tech Clubs", outras não. Em algumas somos participantes centrais e em outras participamos ocasionalmente. Elas estão em todos os lugares e nós pertencemos a várias - e muitas vezes nem percebemos essa participação.

Essas comunidades tanto podem ser pequenas quanto terem muitas pessoas. $\mathrm{O}$ interessante é que por fazerem parte, os participantes sentem-se mais à vontade para arriscar novas descobertas, pois sabem que haverá suporte de outras pessoas tão interessadas quanto eles. Devemos nos atentar, entretanto, ao fato de que nem todas as comunidades são comunidades de prática. Wenger, Mcdermott e Snyder (2002) afirmam que uma conversa em uma viagem de avião não constitui uma comunidade de prática. Os autores dizem que para que haja a constituição de uma, é necessário interagir com regularidade, para que os membros desenvolvam um entendimento compartilhado de seu domínio e uma abordagem para a sua prática. 
Apesar de essas comunidades serem mais informais, elas focam o conhecimento e a aprendizagem. Sua definição pode ser dada através de três palavras: domínio, comunidade e prática. O domínio é o assunto, tópico que interessa a um grupo de pessoas, que seria então uma comunidade. Juntos eles desenvolvem e aprendem mais sobre o domínio que possuem em comum, constituindo assim uma prática. Um exemplo do desenvolvimento dessa prática pode ser encontrado no trabalho de Barcelos (2010). O autor relata o caso de um aluno do ensino fundamental, que se comunicava em inglês com outros jogadores on-line, o que resultava em conhecimento de novas estratégias para o jogo e em aprimoramento da língua inglesa.

Devido aos avanços da tecnologia, as fronteiras geográficas existentes não são mais barreiras para que comunidades de prática surjam em diferentes tocais. As pessoas não precisam ter, necessariamente, encontros presenciais, pois há ferramentas na internet que possibilitam que esses encontros aconteçam no ambiente on-line. Wenger, Mcdermott e Snyder (2002) chamam essas comunidades de comunidades distribuídas. Para os autores esse tipo de comunidade diz respeito a qualquer comunidade de prática que não dependa de encontros presenciais como principal veículo de conexão entre os membros.

Acredito que as redes sociais presentes na web atualmente são ferramentas propícias para que comunidades de prática possam emergir. Facebook, Orkut e Twitter são algumas das mais usadas no Brasil, e englobam pessoas do mundo inteiro. A meu ver, elas constituem-se como macro comunidades de prática que abrigam várias comunidades de prática. Ou seja, várias pessoas se reúnem através desses aplicativos para trocarem ideias sobre tópicos que as interessem.

Podemos perceber ainda que essas ferramentas propiciam um ambiente de aprendizagem situada (LAVE; WENGER, 1991), visto que para pertencer a uma comunidade, você não precisa necessariamente ser um participante ativo; o fato de estar inserido e fazendo parte das discussões abordadas ali, por exemplo, faz com que a pessoa possa, no futuro, participar de forma ativa. Os autores afirmam que a periferalidade é uma posição de empoderamento, ou seja, é uma posição que oferece possibilidades de aprendizagem para que no futuro haja a participação de forma completa.

Braga (2007) mostra que a aprendizagem é desenvolvida, mais produtivamente, em grupos nos quais os integrantes possam interagir e refletir sobre suas experiências mútuas. Seu trabalho tem como foco os chamados grupos de aprendizagem, que segundo Johnson e 
Johnson (1982 apud PAIVA, 2010) têm como propósito assegurar que seus integrantes aprendam uma matéria específica, uma habilidade, um determinado assunto ou um procedimento, tendo como principal objetivo a aprendizagem que acontece nas comunidades de prática.

Sendo assim, acredito que as redes sociais podem propiciar espaço para que grupos de aprendizagem e/ou comunidades de prática surjam, afim de que os participantes troquem informações e aprendam juntos, independentemente do assunto abordado.

\section{Metodologia}

Para Denzin e Lincoln (2006), quem realiza pesquisas qualitativas, coleta materiais empíricos que tenham ligação com a questão a ser estudada, para analisá-los e escrever a seu respeito. Ainda, segundo os autores, a palavra "qualitativa" implica uma ênfase sobre as qualidades das entidades e sobre os processos e os significados que não são examinados ou medidos experimentalmente. A respeito das diferenças entre as duas pesquisas, os autores enfatizam que a primeira ressalta a natureza socialmente construída da realidade, enquanto a segunda enfatiza o ato de medir e de analisar as relações causais entre variáveis, e não processos.

Para Demo (2002), não há a dicotomia entre quantidade e qualidade, porque claramente qualidade provém também de base quantitativa. $\mathrm{O}$ autor afirma que há realidades que podemos chamar de mais qualitativas do que quantitativas, mas todas são mesclas de ambas as dimensões. Classifico a presente pesquisa segundo essa premissa, ou seja, ela é mais qualitativa, embora seja quantitativa também.

É ainda uma pesquisa de orientação etnográfica. O objetivo da pesquisa etnográfica, segundo Erickson (2003) é documentar em detalhe o desenrolar dos eventos cotidianos e identificar os significados atribuídos a eles tanto por aqueles que deles participam, quanto por aqueles que o observam. Ainda segundo o autor, o trabalho idealmente envolve observação e participação de longo prazo no cenário que está sendo estudado, o que não foi feito por mim.

No caso dessa pesquisa, utilizei questionários como forma de documentar as informações necessárias para o desenvolvimento da mesma. Porém, não entrei em contato direto com todos os participantes, visto que alguns são meus alunos e outros não. Por isso, não considero minha pesquisa etnográfica, como descreve Erickson (2003), mas sim de orientação etnográfica. 
O local escolhido para a realização desta pesquisa foi a escola de idiomas na qual trabalho. Ela está localizada na cidade de Uberaba, Minas Gerais. Decidi escolher esse lugar devido à aproximação com os alunos, professores e diretores.

Além da autorização da escola, para que este material pudesse ser usado, precisei da autorização dos participantes também através do Termo de Consentimento Livre e Esclarecido. Foram distribuídos 100 (cem) termos para alunos da instituição. Desses termos entregues, recebi de volta 60 (sessenta), e após a entrega dos questionários, coletei 43 (quarenta e três) para analisar. Observei que o fato de a entrega do termo não ter sido feito juntamente com o questionário atrapalhou. Alguns alunos devolveram o termo, mas não devolveram o questionário.

O questionário aplicado possui diversas questões fechadas e poucas abertas. Porém, as questões nas quais os alunos escreveram foram as que guiaram o trabalho, sendo que as fechadas serviram para confirmá-las. Esse questionário foi produzido pelo GELED ${ }^{4}$, grupo de pesquisa do qual faço parte, porém cada integrante faz as mudanças necessárias de acordo com o objeto de pesquisa.

Dividi a análise a partir das quatro perguntas abertas. Cada uma foi analisada separadamente, e, quando necessário, subdividi as respostas em grupos específicos. Após a análise, procurei entender se as redes sociais nas quais os participantes percebem e efetivam affordances para sua aprendizagem de língua inglesa podem ser consideradas comunidades de prática.

\section{Os recursos tecnológicos e a aprendizagem de língua inglesa.}

Como citado anteriormente, o questionário aplicado aos participantes contém mais questões fechadas do que abertas, porém as últimas foram o foco das análises. Inicio meu relato com a primeira questão aberta:

Os recursos tecnológicos que você usa no dia a dia influenciam sua aprendizagem de língua estrangeira? Caso afirmativo, de que maneira?

Através dessa pergunta refleti se os alunos associam os recursos tecnológicos com a aprendizagem da língua inglesa, e como eles o fazem. Dos 43 (quarenta e três) alunos participantes, obtive 39 (trinta e nove) respostas positivas, e das 4 (quatro) restantes, 3 (três)

\footnotetext{
${ }^{4}$ Grupo de Estudos em Linguagem e Educação Digital.
} 
foram negativas e 1 (uma) ficou em branco. Das respostas positivas, os temas recorrentes de recursos tecnológicos que influenciam a aprendizagem de língua inglesa foram: músicas, vídeos, filmes com legenda, jogos e exercícios de gramática on-line, contato com pessoas em redes sociais, uso de sites de busca, tradução de palavras desconhecidas e de artigos científicos, enriquecimento de vocabulário, e uso de aplicativos em inglês no celular.

Foi interessante observar que os alunos conseguem perceber e efetivar as affordances nos recursos tecnológicos citados por eles para aprendizagem de língua inglesa, principalmente através da internet. Dois comentários que enfatizam essa confirmação estão transcritos a seguir:

\section{Excerto \# 01}

Sim. Na internet posso ter acesso as letras das músicas que eu gosto, com isso já aprendi muitas palavras novas em inglês (G.S $)^{5}$.

\section{Excerto \# 02}

A grande maioria do material e mídia que circula na internet, que é o meio de comunicação que mais uso, está em inglês, por isso é importante compreender esta língua (R.H).

Dentre os participantes que responderam positivamente, 6 (seis) referiram-se às redes sociais presentes na web e aos jogos on-line, como ambientes que ajudam a desenvolver a língua inglesa. Vejamos uma dessas respostas:

\section{Excerto \# 03}

Sim. Porque em todos os sites que navego, seja em redes sociais, jogos ou em pesquisas, eu vejo palavras em inglês e sempre tento traduzi-las (A.O).

O próximo passo foi observar se os participantes utilizavam redes sociais e com qual frequência. Do total, 42 (quarenta e dois) alunos responderam que usam, sendo que 31 (trinta e um) utilizam com frequência e 11 (onze) esporadicamente. Apenas 1 (um) aluno respondeu que não utilizava os aplicativos com frequência.

Outra pergunta questionava os alunos sobre redes sociais específicas. As escolhidas para esse artigo foram Orkut, Facebook, Twitter, Livemocha, Formspring me, Blogger, MSN, Skype e Myspace. Optei por esses aplicativos, pois todos proporcionam comunicação

\footnotetext{
${ }^{5}$ Os nomes de todos os participantes desta pesquisa foram preservados e me refiro a eles apenas com as iniciais de seus nomes.
} 
síncrona e assíncrona, além de serem utilizados por pessoas do mundo inteiro. Transcrevo, a seguir, a pergunta feita aos participantes e as respostas dadas por eles, sistematizadas em um quadro.

Em relação às redes sociais abaixo escreva: (0) nunca usei (1) usei uma vez (2) usei algumas vezes (3) uso frequentemente

QUADRO 1: Uso dos aplicativos pelos participantes

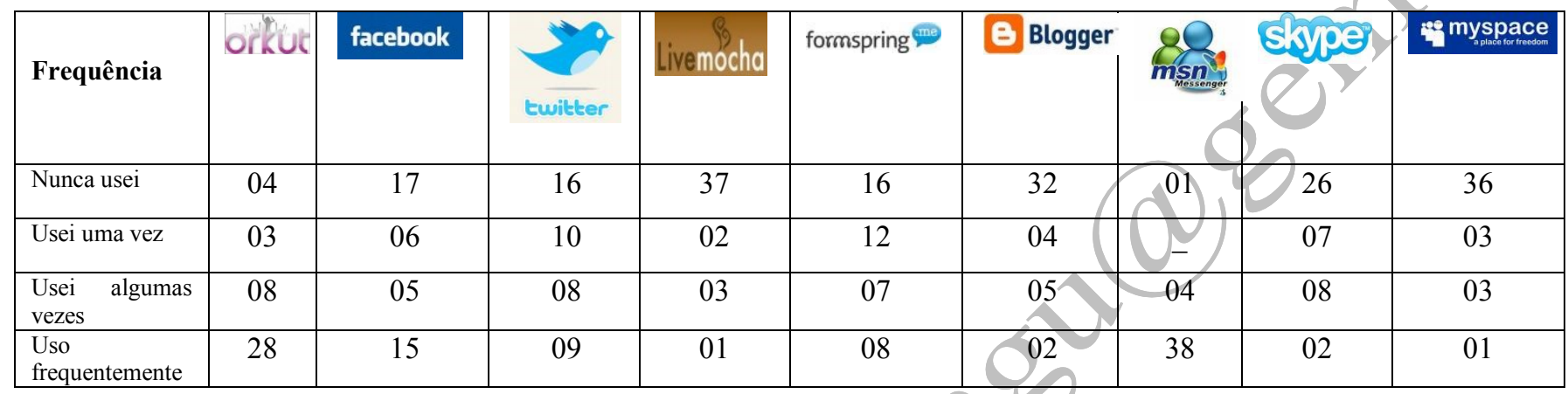

A partir desses dados, interessa-me entender'se os alunos conseguem perceber e efetivar as affordances presentes nesses aplicativos para aprendizagem de língua inglesa. Com o objetivo de obter essa resposta, utilizei a seguinte pergunta para que eles dissertassem a respeito:

Escolha 02 desses aplicativos e conte para nós alguma experiência positiva ou negativa que teve ao usar esses aplicativos. Dentre as experiências, tente lembrar se alguma delas envolveu o uso de outra língua que não seja o português. Faça um relato e conte para nós sobre essas experiências.

Dividi as respostas em quatro grupos cujos participantes apresentaram características similares entre si.

\subsection{Grupo 1: Participantes deixaram a resposta em branco}

O primeiro grupo foi formado por 2 (dois) participantes, que não responderam a pergunta. Ambos escreveram que usam redes sociais, um com frequência, o outro não. $\mathrm{Na}$ primeira pergunta aberta, um respondeu que os recursos tecnológicos ajudam a aprender uma língua estrangeira através do áudio e o outro disse que "mais ou menos, porque algumas das atividades eu dependo do computador". Através das perguntas fechadas, percebi que eles 
nunca se comunicaram em língua inglesa no ambiente on-line. Interpretei que eles não percebem as possibilidades que esses aplicativos possuem para aprendizagem de outra língua.

\subsection{Grupo 2: Participantes usam os aplicativos, mas não os utilizam para a aprendizagem de língua inglesa.}

O segundo grupo compreendeu 19 (dezenove) alunos, que afirmaram usar os aplicativos, mas a maioria não os associou com a aprendizagem da língua inglesa. Voltando à primeira pergunta aberta, na qual eles discorreram sobre os recursos tecnológicos que influenciam sua aprendizagem, nenhum deles citou as redes sociais. Eles utilizam os aplicativos como forma de comunicação com colegas e familiares - muitos citaram que é uma forma de economizar em ligações telefônicas. Gostam também de fazer novas amizades, mas sempre com pessoas brasileiras, interagindo em língua portuguesa como podemos observar nos excertos a seguir:

\section{Excerto \# 04}

Facebook e Messenger, são os aplicativos em que comunico com amigos para encontra-los em torneios de tênis. Porém, não envolve o uso de outra língua que não seja o português (L.F).

\section{Excerto \# 05}

MSN: excelente para comunicação no trabalho, economizando em ligações telefônicas, visto que a empresa onde trabalho possui filiais e vários clientes em todo o país. Forma rápida de envio de arquivos. Economia de tempo. Facebook: ótimo para comunicação com amigos, assuntos de interesse, família, grupos, empresas, etc. (M.E).

Alguns participantes percebem as affordances relacionadas à aprendizagem de língua inglesa, mas não as efetivam. O participante P.O, por exemplo, afirmou que usa o Twitter e o MSN, e que nunca teve experiências negativas, porém nunca se comunicou com pessoas que falam outras línguas para adquirir mais conhecimento sobre elas. $\mathrm{O}$ aluno sabe, então, que existe a possibilidade de melhorar o idioma através dessas redes sociais, mas aparenta não ter interesse.

Já outra participante, assim como P.O, demonstrou perceber as affordances, e lamenta não ter tido a oportunidade ainda de usar a língua inglesa nesses ambientes:

\section{Excerto \# 06}

No Orkut e no MSN já reencontrei amigos e pessoas queridas que não tinha contato há muito tempo. Mas também pessoas das quais não queria mais entrar em contato me encontraram (embora sejam pouquíssimas) e essa foi um experiência 
ruim. Infelizmente ainda não tive oportunidade de conversar com meus amigos em outras línguas (C. C).

\subsection{Grupo 3: Participantes utilizam os aplicativos para a aprendizagem da língua inglesa:}

Dentre os participantes, 20 (vinte) relacionaram as redes sociais como ambientes que podem proporcionar a aprendizagem da língua inglesa, inclusive aqueles que já haviam comentado sobre elas na primeira pergunta aberta.

Foi possível perceber que em um mesmo aplicativo, os alunos efetivam diferentes affordances, confirmando assim quando Paiva (2010) aponta que affordances não são propriedades dos ambientes. Vejamos a seguir dois depoimentos acerca do uso do Twitter:

\section{Excerto \# 07}

Twitter: quando comecei a usar o twitter muitas palavras eu desconhecia da língua inglesa isso me fez procurar seus significados e ampliar meu campo linguístico em inglês (L.C).

\section{Excerto \# 08}

Twitter: Hoje mesmo eu segui uma menina estrangeira e ela também me seguiu e nos ficamos conversando em inglês e agora somos amigas (A.F).

Uma participante utiliza a rede social como forma de ampliar seu vocabulário, enquanto a outra a vê como oportunidade de se comunicar na língua e fazer novas amizades com pessoas de outros países. Outro participante afirma que gosta de visitar páginas de famosos nessa rede social para saber o que eles estão fazendo, sendo assim um participante periférico (LAVE; WENGER, 1991), porém adquirindo conhecimentos acerca da língua nessa posição periférica.

Muitos participantes não fazem questão de conversar com nativos em inglês através desses aplicativos, mas conversam em inglês com colegas para melhorar o idioma, e outros com brasileiros que moram nos Estados Unidos. Uma das questões fechadas indagava se os alunos já tinham conversado com um nativo e se haviam gostado da experiência. Trinta e uma respostas foram negativas, o que me leva a interpretação de que os alunos não vêem essa comunicação como um meio importante para aprimorar a língua inglesa.

Pedi, também, para os alunos apontarem pontos negativos desses aplicativos e observei que alguns percebem que há pessoas mal intencionadas, que utilizam perfis falsos. Uma participante disse que atualmente temos o bullying virtual, e que isso a incomoda. Outra 
experiência negativa foi apontada por T.F. ao afirmar que se frustrou ao tentar fazer seu perfil no Twitter, pois tudo estava em inglês e ela não conseguiu. Apesar dessa experiência, ela utiliza a língua inglesa no MSN, como podemos observar nos excertos a seguir:

\section{Excerto \# 09}

No Orkut eu conheci várias pessoas de outros países mas sempre me comuniquei com elas através da língua inglesa, a única coisa ruim é que existem pessoas mal intencionadas (G.S).

\section{Excerto \# 10}

Twitter: me frustrei ao tentar usar o Twitter sem o domínio da língua inglesa não consegui me cadastrar. MSN. Após dar inicio ao meu curso de inglês, comecei a fazer amigos no MSN utilizando a língua inglesa (T.F).

Sendo assim, esse grupo de alunos demonstrou que efetiva diferentes affordances nesses ambientes on-line, praticando a língua estudada por eles.

\subsection{Grupo 4: Participantes utilizaram os aplicativos para a aprendizagem de língua inglesa, porém não gostaram.}

Dentre todos os participantes, 2 (dois) perceberam e efetivaram affordances em redes sociais, mas não tiveram uma experiência positiva. Para discorrermos a respeito deles, vejamos seus depoimentos:

Excerto \# 11

Uma vez experimentei o MSN e Orkut na língua inglesa, mas como havia muitas palavras que eu não conhecia, voltei ambas para português (V.F).

Excerto \# 12

Uma vez uma pessoa com email diferente me adicionou no MSN e começou a conversar comigo em inglês. Conversei com ele normalmente até que ele começou a perguntar exatamente onde eu morava, a perguntar informações pessoais que não tive coragem de responder. Com a insistência, exclui-o de meu MSN e nunca mais adicionei nenhum estrangeiro (C.P).

O primeiro aluno tentou usar os aplicativos para melhorar o idioma, mas desistiu. Mudar a interface para a língua inglesa tornou-se um desafio para muitos do grupo 3, mas para ele foi uma desmotivação, o que fez que ele voltasse ambas as páginas para o português.

Já a segunda participante, no início, estava utilizando a rede social para melhorar o seu inglês. Porém, devido às perguntas feitas pelo novo amigo adicionado, a aluna ficou com medo e nunca mais adicionou uma pessoa estrangeira. 


\section{Aplicativos Tecnológicos no contexto escolar}

A próxima pergunta aberta feita aos participantes foi relacionada ao uso desses aplicativos dentro da sala aula. Através dela, procurei saber se os alunos já tiveram a oportunidade de praticar alguma matéria através das redes sociais, e como foi essa experiência.

Você já utilizou algum desses aplicativos na sala de aula? Caso afirmativo, em quais disciplinas (inglês, português, matemática, etc.)? Poderia nos contar que tipo de atividade o(a) professor(a) desenvolveu com a turma? Você gostou dessa experiência? Por quê?

Diferentemente de como fiz com a pergunta anterior, dividi as respostas em dois grupos. Antes da análise, é necessário salientar que, como professora dessa instituição, realizei uma atividade com meus alunos com um desses aplicativos e alguns dos participantes dessa pesquisa fazem parte desse grupo.

\subsection{Grupo 1: Participantes responderam que nunca utilizaram esses aplicativos em sala de aula.}

Dentre todos os participantes, 34 (trinta e quatro) responderam que não. Desse total, 32 (trinta e dois) escreveram apenas "não" como resposta. Porém, 1 (uma) participante nos chamou a atenção ao responder da seguinte maneira:

\section{Excerto \# 13:}

Acho que seria muito interessante, no entanto nunca tive a oportunidade de estar presente em uma aula com tais recursos (N.C).

$\mathrm{Na}$ resposta transcrita anteriormente, a aluna tem interesse em ter uma aula que envolva atividades com as redes sociais, mas nenhum professor lhe proporcionou isso.

\subsection{Grupo 2: Participantes já usaram esses aplicativos em sala de aula:}

Apenas 9 (nove) alunos responderam que já tiveram a oportunidade de utilizar algum aplicativo dentro da sala de aula. Dentre eles, 8 (oito) são meus alunos e tiveram essa experiência apenas comigo.

Por perceber a deficiência dos alunos para elaborar perguntas em inglês e usar os auxiliares corretos, propus que cada um fizesse um perfil no Formspring me. Nesse programa, 
os usuários trocam perguntas sobre qualquer assunto, e as respostas podem ser lidas por todos os amigos adicionados.

Escolhi esse aplicativo justamente pelo fato dele ser um ambiente específico para fazer perguntas. $\mathrm{O}$ objetivo era que os alunos participassem toda semana e fizessem perguntas aos colegas relacionadas ao que estávamos aprendendo em sala de aula. Dos alunos que participaram ativamente, percebi que a atividade foi positiva, pois os depoimentos indicam que eles gostaram da atividade proposta.

\section{Excerto \# 14}

Sim, inglês. Usamos o formspring para fazer perguntas sobre a matéria estudada no momento. Gostei da experiência pois é um meio de nós percebermos onde estamos errando (I.R).

\section{Excerto \# 15}

Sim, usamos o formspring, nós tínhamos que nos comunicar em inglês com os alunos da sala. Eu gostei da experiência, porque além de conhecer melhor meus colegas, pude praticar o idioma (G.S).

A única participante que não fazia parte do grupo dos meus alunos utilizou um aplicativo para aprender física na escola regular. Apesar de não dizer o nome do aplicativo, a aluna demonstrou interesse pela atividade proposta pelo professor e informa ter aprendido a matéria considerada difícil por ela.

\section{Excerto \# 16}

Sim, em física uma vez utilizamos um aplicativo para entender o movimento das ondas em ondulatória. Eu gostei da experiência, pois saiu da ideia redundante da sala de aula que, especialmente em física (não era uma matéria considerada por mim muito prazerosa) me deu um pouco mais de interesse e curiosidade pela matéria em questão para tentar aprendê-la (C.P).

\section{Jogos on-line e a aprendizagem de língua inglesa.}

A última questão aberta foi relacionada a jogos on-line.

Você joga games on-line? Caso afirmativo, há interação entre você e outras pessoas através da língua inglesa? Conte-nos sua experiência.

Como já citado anteriormente, Barcelos (2010) mostra que um aluno do ensino fundamental se destacou entre os demais nas aulas de inglês, pela sua experiência com jogos 
on-line. $\mathrm{O}$ autor afirma que as affordances efetivadas nesse jogo possibilitaram a emergência de um perfil de aluno usuário ativo da língua estrangeira no e fora do ambiente escolar.

$\mathrm{Na}$ presente pesquisa, dos 43 (quarenta e três) participantes, 29 (vinte e nove) responderam que não jogam on-line. Em contrapartida, obtive 14 (quatorze) respostas positivas. Dos alunos que jogam on-line, 2 (dois) responderam apenas positivamente e negativamente, indicando que eles jogam, mas não utilizam a língua inglesa nesse ambiente. Como ilustrado pelo excerto a seguir, 2 (dois) outros participantes responderam que jogam sozinhos, não havendo assim possibilidade de interação com alguém.

\section{Excerto \# 17}

Sim. Bom, quando eu jogo, eu jogo sozinha, então, eu nunca conversei com ninguém (A.F).

Outros 12 (doze) participantes responderam afirmativamente que interagem com outras pessoas na língua inglesa. Os alunos perceberam que através do bate papo presente nesses jogos, é possível se comunicar com pessoas estrangeiras, e, assim, especialmente no que se refere ao vocabulário dessa língua, melhorar o inglês. Apresento a seguir dois excertos que ilustram essa aprendizagem:

\section{Excerto \# 18}

Sim, os chats são do mundo todo. Então aprendemos vários vocabulários (F.R).

\section{Excerto \# 19}

Sim, jogo xadrez no gamezer.com e sempre me deparo com pessoas estrangeiras. Sempre nos comunicamos através do chat do site e trocamos e-mails (A.C).

A aluna A.C vai além dos jogos e continua sua comunicação através de e-mails. Outra participante percebe que nesse ambiente as pessoas escrevem de forma culta e informal, mostrando assim possuir conhecimento sobre a língua.

\section{Excerto \# 20}

Sim, jogo. Algumas pessoas conversam e digitam o inglês certo e formal, mas tem muitas pessoas que abreviam ou usam gírias para conversar (A.O).

$\mathrm{O}$ participante V. F respondeu que apenas uma vez tentou se comunicar em inglês através de um jogo, com a ajuda do tradutor. Porém, como a pessoa estrangeira usava muitas gírias, a comunicação não ocorreu de forma satisfatória.

Excerto \# 21

Sim, houve apenas uma vez em que conversei com alguém da língua inglesa com 
o auxílio do tradutor, mas, por utilizar gírias não consegui me comunicar direito (V.F).

Assim como Barcelos (2010), acredito que os jogos on-line, nos quais haja principalmente interação através de bate papo, são ambientes repletos de affordances a serem percebidas e efetivadas para aprendizagem de língua inglesa.

A partir das reflexões apresentadas nas últimas seções, me questionei se, no contato com as redes sociais mencionadas por esses alunos, eles passaram a fazer parte de comunidades de prática. Abordo essa discussão na próxima seção.

\section{De redes sociais a comunidades de prática: há essa emergência?}

Retomemos o conceito de comunidades de prática de Wenger, Mcdermott e Snyder (2002), no qual os autores dizem que elas são grupos de pessoas que dividem mesmos problemas ou paixão por um tópico. As redes sociais usadas pelos alunos que participaram dessa pesquisa são ambientes que proporcionam o surgimento de comunidades distribuídas. Porém, o envolvimento dos alunos os levou à participação efetiva em comunidades de prática on-line?

A meu ver, as redes sociais ajudam os alunos a melhorar o idioma, mas elas tendem a não ser usadas como comunidades de prática. Apesar de aprenderem vocabulário e praticarem o idioma com outras pessoas nessas redes sociais, não há um tópico específico sobre o qual os participantes informem discutir. Muitas vezes, eles não demonstraram estar ali para melhorar o conhecimento sobre a língua inglesa, mas sim para fazer novas amizades, não constituindo, assim, uma comunidade de prática nos termos de Wenger, Mcdermott e Snyder (2002).

Além disso, os referidos autores afirmam que os integrantes dessas comunidades devem se tornar parceiros de aprendizagem. Os alunos pesquisados, por não entrarem em contato com outras pessoas por diferentes interesses, demonstraram não criar vínculos com os participantes. O depoimento do excerto 22 mostra que a participante teve oportunidades de conversar com nativos, mas não indica que manteve contato com eles, nem que tinham interesse e discutiam sobre um assunto comum.

\section{Excerto \# 22}

Orkut e MSN. Já pude conversar com pessoas que falam fluentemente o inglês e que são nativos de outros países. Também já conversei pessoalmente com o namorado de uma prima minha, ele é americano e domina muito pouco o português (A.O). 
Apenas a aluna A.C. aparentou utilizar redes sociais on-line como comunidades de prática, segundo conceito de Wenger, Mcdermott e Snyder (2002).

Excerto \# 23

Myspace: fiz muitos amigos nos Estados Unidos que possuem bandas e sempre me mantém "antenada" do que está rolando de novo no país. Livemocha: utilizo com muita freqüência para estudar e sempre fazendo amigos e fazendo uso dos recursos de aprendizagem (A.C).

A participante mantém contato com os colegas para saber sobre as novidades de bandas de seu interesse, mas não fica claro se há prática, isto é, se eles constroem conhecimento juntos. No outro aplicativo, também não foi possível evidenciar se ela mantém amizade com os usuários da rede social citada e se juntos ampliam e discutem a aprendizagem de língua inglesa proporcionada pelo site.

Wenger, Mcdermott e Snyder (2002) enfatizam que uma comunidade que não foca na construção de uma prática compartilhada será apenas um grupo difuso de amigos que socialmente podem se satisfazer, mas é ineficiénte. Sendo assim, concluo que apesar dessas redes sociais oferecerem um ambiente propício para emergência de comunidades de prática, a maioria dos participantes dessa pesquisa não as utiliza como tal.

\section{Considerações Finais}

Este artigo buscou responder duas questões. A primeira é como alunos de uma escola de idioma da cidade de Uberaba, Minas Gerais, percebem e efetivam as affordances presentes no ambiente on-line para a aprendizagem de língua inglesa. Do total de participantes, 39 (trinta e nove) demonstraram perceber as possibilidades existentes através desse ambiente e aproveitá-las para melhorar o idioma que estão aprendendo. Relembrando que Paiva (2010) afirma que as affordances não são propriedades dos ambientes, e sim um resultado da interação entre eles as pessoas. Isso foi visto nos participantes e nas diferentes affordances efetivadas por eles no ambiente on-line, incluindo uso de vídeos, músicas, redes sociais, jogos etc.

A segunda pergunta era se para esses alunos, as redes sociais nas quais eles percebem e efetivam affordances para sua aprendizagem de língua inglesa podem ser consideradas comunidades de prática. Através das análises das perguntas feitas, descobri que essas redes sociais tendem a não serem usadas como comunidades de prática. Muitos alunos percebem e 
efetivam affordances em redes sociais para aprendizagem de língua inglesa. Porém, a inserção em uma comunidade de prática parece ser mais complexa do que imaginava no início da pesquisa. Apenas uma participante aparentou fazer parte de comunidade de prática, mas, devido às limitações dessa pesquisa, não foi possível investigá-la mais a fundo. Um dos encaminhamentos em outras pesquisas seria encontrar situações na qual isso aconteceu e investigar esses contextos mais amplamente.

Com os resultados obtidos nesse trabalho, acredito que é cada vez mais necessária a reflexão sobre o ensino de línguas estrangeiras mediado pelas novas tecnologias. Relembrando ainda a fala de Prensky (2001), os nativos digitais não irão retroceder, mas cabe aos pais e professores orientá-los para que possam aproveitar de forma crítica e produtiva das possibilidades oferecidas pelo ambiente on-line, percebendo e efetivando affordances para a contínua produção de conhecimento, inclusive no que se refere ao inglês como língua estrangeira.

\section{Referências}

BARCELOS, F.A.A. Aprendendo inglês em jogos on-line: um relato sobre nativos digitais. 19f. Trabalho de conclusão de curso (TCC) - Letras, Universidade Federal do Triângulo Mineiro, Uberaba, 2010.

BRAGA, J.C.F. Comunidades autônomas de aprendizagem on-line na perspectiva da complexidade. 207f. Tese (Doutorado) - Letras, Universidade Federal de Minas Gerais, Belo Horizonte, 2007.

BRASIL. Linguagens, códigos e suas tecnologias. Brasília: Ministério da Educação, Secretaria de Educação Básica, 2006.

DEMO, P. Complexidade e aprendizagem: a dinâmica não-linear do conhecimento. São Paulo: Editora Atlas, 2002. 195 p.

DENZIN, N; LINCOLN, Y. O planejamento da pesquisa qualitativa: teorias e abordagens. 2 ed. Porto Alegre: Artmed, 2006.

DUDENEY, G. The internet and the language classroom: a practical guide for teachers. Cambridge University Press, 2000.

ERICKSON, F. Prefácio. In: COX, M.I.P.; PETERSON, A.A.A. (Org.). Cenas de sala de aula. Campinas (SP): Mercado de Letras, 2003.

GIBSON, J. J. The ecological approach to visual perception. Hillsdale: Lawrence Erlbaum Associates, 1986. 
LAVE, J; WENGER, E. Situated learning: legitimate peripheral participation. New York: Cambridge University Press, 1991.

LIMA, D.C. (Org.). Ensino e aprendizagem de língua inglesa: conversa com especialistas. São Paulo: Parábola Editorial, 2009.

LONGMAN: Dictionary of American English. Pearson Education Limited, 2004.

PAIVA, V. L. M. O. Affordances beyond the classroom. (2010) Disponível em:

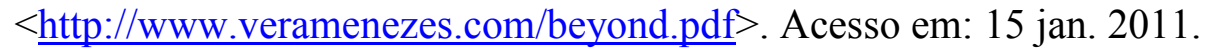

PRENSKY, M. Digital natives, digital immigrants. On the Horizon, v. 9, n. 5,2001.

VAN LIER, L. The Ecology and semiotics of language learning: a sociocultural perspective. Dordrecht: Kluwer Academic Publishers, 2004.

WENGER, E.; MCDERMOTT, R.; SNYDER, W. M. Cultivating communities of practice: a guide to managing knowledge. Massachussets: Harvard Business School Press, 2002.

YOUNG, M. F.; BARAB, S. A.; GARRET, S. Agent as detector: an ecological perspective on learning by perceiving-doing acting systems. In: JONASSEN, D. H.; LAND, S. M. (Ed.). Theoretical foundations of learning environments. Mahwah; London: Lawrence Erlbaum Associates, 2000. p. 147-171.

Artigo recebido em: 15.10 .2012

Artigo aprovado em: 20.11.2012 